\title{
Effect of Developed Low Cost Minimal Medium on Lipid and Exopolysaccharide Production by Lipomyces starkeyi Under Repeated Fed-batch and Continuous Cultivation
}

\author{
V. Thirumal, ${ }^{a}$ A. Chistoserdov, ${ }^{\mathrm{b}}$ R. Bajpai, ${ }^{\mathrm{a}}$ \\ J. Bader, ${ }^{\mathrm{c}}$ M. K. Popovic, ${ }^{\mathrm{c}}$ and R. Subramaniam ${ }^{\mathrm{a},{ }^{,}}$ \\ ${ }^{a}$ Department of Chemical Engineering, University of Louisiana \\ at Lafayette, Lafayette, LA 70503, USA \\ ${ }^{b}$ Department of Biology, University of Louisiana at Lafayette, \\ Lafayette, LA 70503, USA \\ 'Beuth University of Applied Sciences, Life Sciences \\ and Technology, Biotechnology, Berlin, Germany
}

doi: 10.15255/CABEQ.2018.1389

Original scientific paper

Received: May 26, 2018

Accepted: December 12, 2018

\begin{abstract}
The main objective of this study was to investigate the effects of a low cost minimal medium, developed by the UL Bioprocessing Lab, on the cultivation of Lipomyces starkeyi NRRL Y-11557 using repeated fed-batch and continuous fermentation strategies. The highest cell and lipid concentrations obtained were $22.7 \mathrm{~g} \mathrm{~L}^{-1}$ and $11.67 \mathrm{~g} \mathrm{~L}^{-1}$ under repeated fed-batch cultivation, respectively. Continuous cultivation with the dilution rate of $0.06 \mathrm{~h}^{-1}$ presented the highest cell $\left(0.401 \mathrm{~g} \mathrm{~g}^{-1}\right)$ and lipid yields $\left(0.177 \mathrm{~g} \mathrm{~g}^{-1}\right)$. Exopolysaccharide production was observed when $L$. starkeyi was cultivated in the minimal media supplemented with $90 \mathrm{~g} \mathrm{~L}^{-1}$ glucose under repeated fed-batch fermentation. The produced exopolysaccharide is likely composed of 4-5 repeating sugar units, incorporating mannose and galactose and their respective uronic acids.
\end{abstract}

Keywords:

minimal medium, Lipomyces starkeyi, lipid, exopolysaccharide, fed-batch mode, continuous mode

\section{Introduction}

The oleaginous yeast Lipomyces starkeyi is a species originally isolated from soil, belonging to order Saccharomycetales. It has been shown to accumulate up to $80 \%$ of its dry biomass as lipids under defined culture conditions ${ }^{1,2}$. In addition, it is an attractive microorganism for the production of microbial lipids due to its capacity to utilize a variety of carbon sources, including D-glucose, L-arabinose, D-xylose, D-galactose, D-fructose, D-mannose, D-cellobiose, and sucrose ${ }^{3-5}$. Furthermore, the lipid profile produced by L. starkeyi is optimal for the production of biodiesel, since it is mainly composed of neutral lipids ${ }^{6}$. Cell densities up to $85 \mathrm{~g} \mathrm{~L}^{-1}$ have been reported in a repeated fed-batch cultivation of L. starkeyi DSM 70296, with a lipid concentration of $36.7 \mathrm{~g} \mathrm{~L}^{-1}$. In addition, the cell productivity of $0.6 \mathrm{~g} \mathrm{~L}^{-1} \mathrm{~h}^{-1}$ accompanied by the lipid productivity of $0.288 \mathrm{~g} \mathrm{~L}^{-1} \mathrm{~h}^{-1}$ were reported for L. starkeyi DSM 70296 during continuous cultivation with $60 \mathrm{~g} \mathrm{~L}^{-1}$

"Corresponding author: E-mail: raams@louisiana.edu, raams76@gmail.com sugar concentration in the medium with a dilution rate of $0.06 \mathrm{~h}^{-17}$.

In general, the production of lipid by oleaginous microorganisms can be divided into two phases: cell growth and lipid production ${ }^{8}$. Since the alternatives to the batch process, such as feed batch, repeated fed-batch and continuous, make it possible to control the growth and lipid accumulation phases by modifying the feed, they are important strategies in the pursuit of economical lipid production. For example, the exhaustion of nitrogen sources during the late stages of the fed-batch process results in a reduction in cell growth rate and channeling of the carbon flux towards lipid biosynthesis ${ }^{9}$. Therefore, the ratio of carbon to nitrogen $(\mathrm{C} / \mathrm{N}$ ratio) is an important factor in the onset and level of lipid production. As a general trend, higher $\mathrm{C} / \mathrm{N}$ ratios result in increased lipid and byproduct formation ${ }^{10,11}$. However, nitrogen depletion in the medium can also result in the production of unwanted byproducts. $L$. starkeyi has been reported by Slodki and Wickerham $^{12}$ to be capable of exopolysaccharide production. Continuous cultivation can achieve high cell and lipid productivities with minimal exopolysac- 
charide production ${ }^{7}$ but has its own drawbacks in the form of a susceptibility to contamination, incomplete utilization of substrate, and increased working volumes ${ }^{13}$.

The lipid yield, volumetric productivity, and economics of lipid production are all critically affected by the composition of the fermentation medium. Research into L. starkeyi cultivation has typically utilized yeast extract as a source of vitamins and trace minerals ${ }^{14,15}$. Naganuma et al. ${ }^{4}$ demonstrated that certain constituents of yeast extract can have both positive and negative effects on lipid content and lipid yield, respectively. For example, $\mathrm{Zn}^{2+}$ deficiency increased lipid content by a factor ranging from 2.4 to 2.8 compared to standard zinc concentrations ${ }^{4}$. In contrast, a sufficient supply of $\mathrm{Mn}^{2+}$ increased total cell number by a factor ranging from 1.5 to 1.7 compared to standard manganese concentrations ${ }^{4}$.

A recent work by Subramaniam and Bajpai ${ }^{16}$ has established that the yeast extract is a major cost contributor to the production of microbial lipids, and can be substituted by a combination of biotin, inositol, and calcium pantothenate. Furthermore, the concentration of phosphate salts in the medium can be reduced by $95 \%$ without affecting cell growth, lipid production or lipid composition in a batch culture ${ }^{17}$. In combination, this minimal medium (MM) developed by the UL Bioprocessing Lab reduces the medium cost for lipid production by $L$. starkeyi from 3.35 US $\$ \mathrm{~L}^{-1}$ lipids to $0.82 \mathrm{US} \$ \mathrm{~L}^{-1}$ lipids $^{2}$. The effect of the minimal medium on cell growth and lipid production by $L$. starkeyi under batch cultivation has been studied by Rahman et $a l^{2}$, but the effect on other modes of fermentation is lacking in the literature. Therefore, the present study focused on evaluating the effects of the minimal medium on $L$. starkeyi fermentation using different cultivation strategies, specifically repeated fedbatch cultivation and continuous cultivation, and analyzing the products.

\section{Materials and methods}

\section{Strain and media}

The oleaginous yeast $L$. starkeyi NRRL Y-11557 was used throughout this study. Lyophilized cells were purchased from the American Type Culture Collection (ATCC, Manassas, VA, USA) and revived using yeast mold (YM) medium (composition: malt extract $3 \mathrm{~g} \mathrm{~L}^{-1}$, yeast extract $3 \mathrm{~g} \mathrm{~L}^{-1}$, dextrose $10 \mathrm{~g} \mathrm{~L}^{-1}$, and peptone $5 \mathrm{~g} \mathrm{~L}^{-1}$ ). The cells were then cultivated on YM-agar slants (YM medium with $2 \%$ agar) at $30^{\circ} \mathrm{C}$ in an Isotemp Standard
Lab Incubator (Fisher Scientific, USA) for $48 \mathrm{~h}$, and stored at $4{ }^{\circ} \mathrm{C}$. These stock cells were propagated every month.

The composition of the MM was (per liter): $30 \mathrm{~g}$ of glucose, $0.35 \mathrm{~g}$ of $\mathrm{KH}_{2} \mathrm{PO}_{4}, 0.125 \mathrm{~g}$ of $\mathrm{Na}_{2} \mathrm{HPO}_{4} \cdot 7 \mathrm{H}_{2} \mathrm{O}, 0.5 \mathrm{~g}$ of $\left(\mathrm{NH}_{4}\right)_{2} \mathrm{SO}_{4}, 1.5 \mathrm{~g}$ of $\mathrm{MgSO}_{4} \cdot 7 \mathrm{H}_{2} \mathrm{O}, 0.1 \mathrm{~g}$ of $\mathrm{CaCl}_{2} \cdot 2 \mathrm{H}_{2} \mathrm{O}, 8.2 \mathrm{mg}$ of $\mathrm{FeSO}_{4}, 10 \mathrm{mg}$ of $\mathrm{ZnSO}_{4} \mathrm{H}_{2} \mathrm{O}, 7 \mathrm{mg}$ of $\mathrm{MnSO}_{4}, 10$ $\mathrm{mg}$ of $\mathrm{CuSO}_{4}, 9.41 \mathrm{mg}$ of $\mathrm{CoCl}_{2} \cdot 6 \mathrm{H}_{2} \mathrm{O}, 3 \mathrm{mg}$ of $\mathrm{Bi}$ otin, $3 \mathrm{mg}$ of Inositol, and $0.6 \mathrm{mg}$ of calcium pantothenate. The listed medium composition results in a $\mathrm{C} / \mathrm{N}$ ratio of 113 on a mass/mass basis. In order to prepare medium with a $\mathrm{C} / \mathrm{N}$ ratio of 56 , the concentration of $\left(\mathrm{NH}_{4}\right)_{2} \mathrm{SO}_{4}$ was doubled to $1 \mathrm{~g} \mathrm{~L}^{-1}$.

\section{Culture conditions}

For experiments, inoculation culture was prepared by streaking freshly prepared YM-agar slants with refrigerated cells and incubating them at $30^{\circ} \mathrm{C}$ for $48 \mathrm{~h}$. A loop full of cells from these slants was used to inoculate $125 \mathrm{~mL}$ of sterile MM medium in a $500-\mathrm{mL}$ baffled flask (seed flask-1). Following 48 $\mathrm{h}$ incubation in an orbital shaker at $140 \mathrm{rpm}$, the cells in seed flask-1 were used to inoculate seed flask-2 (at $2 \% \mathrm{v} / \mathrm{v}$ ) also containing $125 \mathrm{~mL}$ of the MM. Seed flask-2 was then incubated in the orbital shaker at $140 \mathrm{rpm}$ for $30 \mathrm{~h}$ before being used to inoculate a fermenter with $2.5 \% \mathrm{v} / \mathrm{v}$ for the repeated fed-batch and continuous cultivation. The seed culture was examined under a microscope to check for any possible contamination before inoculation. For the repeated fed-batch cultivation, a 5-L glass fermenter (New Brunswick, BIOFLO 2000) was used with the 2-L working volume. A 1.2-L glass fermenter (New Brunswick, BIOFLO 310) with the 1-L working volume was used for the continuous cultivation. In both fermenters, the air flow rate was 1 volume per volume per minute (vvm), and the temperature and $\mathrm{pH}$-value were controlled at $30^{\circ} \mathrm{C}$ and 5.5 , respectively. An amount of $0.5 \mathrm{M}$ sodium hydroxide solution was used to maintain $\mathrm{pH}$-value during cultivations.

The MM was used during continuous cultivation for both the initial culture as well as the feeding media. The dilution rate was controlled by varying the medium flow rate. Dilution rates of $0.02 \mathrm{~h}^{-1}$ and $0.06 \mathrm{~h}^{-1}$ were investigated in this study. Continuous feeding was started following $24 \mathrm{~h}$ or $72 \mathrm{~h}$ of batch cultivations. The repeated fed-batch cultivation used the MM with $90 \mathrm{~g} \mathrm{~L}^{-1}$ glucose for the initial culture, and a pure glucose solution was used for each feeding to maintain the glucose concentration in the culture to $30 \mathrm{~g} \mathrm{~L}^{-1}$. Feeding times were determined when glucose concentration fell below $1 \mathrm{~g} \mathrm{~L}^{-1}$. 


\section{Analytical methods}

\section{Cell concentration}

Cell concentrations in samples were determined by measuring a culture optical density using a DR 1500 UV-Vis spectrophotometer (Hach Company, USA) at $570 \mathrm{~nm}$. Samples for cell concentration measurements were collected at variable time intervals $(8$ to $24 \mathrm{~h})$. All the measurements were conducted in triplicate. Cell dry mass (CDM) of cells was measured in cultures at the end of the cultivation, and optical density vs. CDM concentration calibration curve was prepared using appropriately diluted cell suspensions. The calibration curves were used to convert optical density into cell concentrations $\left(\mathrm{g} \mathrm{CDM} \mathrm{L}^{-1}\right)$.

\section{Lipid analysis}

Lipids in the samples were measured using the Nile red fluorescence method ${ }^{18}$ using a Shimadzu spectrofluorophotometer (RF-1501, Shimadzu Corporation, Japan). At the end of each fermentation, cells were recovered from broth, and the Bligh and Dyer lipid extraction method was used ${ }^{19}$. Calibration curves relating sample lipid content vs. fluorescence intensity were then prepared for both fermenters and used to translate fluorescence into lipid concentrations (g lipid $\mathrm{L}^{-1}$ ).

\section{Carbohydrate separation and analysis}

The culture samples were filtered through a $0.45 \mu \mathrm{m}$ filter, and the filtrate was added to chilled ethanol at a 1:19 ratio (v/v). Following $2 \mathrm{~h}$ incubation in the freezer, the solution was centrifuged at $12,000 \mathrm{~g}$ for $10 \mathrm{~min}$ (SorvallStratos Benchtop Centrifuge - Thermo Fisher Scientific, U.S.A.), and the pellet (if any) was separated from the supernatant. The supernatant was analyzed for glucose concentration using the Daines colorimetric method ${ }^{20}$, and a calibration curve relating absorbance and glucose concentration was used to report glucose concentration (g glucose $\mathrm{L}^{-1}$ ). The pellet was suspended in deionized water and analyzed for polysaccharides using the phenol-sulfuric acid method ${ }^{21}$. A calibration curve was then prepared for absorbance vs. polysaccharide concentration, and used to translate the absorbance into polysaccharide concentrations (g polysaccharide $\mathrm{L}^{-1}$ ).

\section{Fourier Transform Infrared (FTIR) analysis}

Sample was freeze dried for $48 \mathrm{~h}$, before FTIR spectroscopy was conducted in the Chemistry Department at UL Lafayette on an Agilent Cary 630 FTIR spectrometer with the wave number region of $400-4000 \mathrm{~cm}^{-1}$ used to determine the functional groups of polysaccharides produced.

\section{MALDI-TOF MS analysis}

MALDI-TOF MS was performed by the Murray Mass Spectroscopy group in the Department of Chemistry, Louisiana State University.

\section{Spheroplast production}

The culture sample was centrifuged at 7500 rpm for $15 \mathrm{~min}$ and washed with deionized water twice, before digesting using the Zymolyase 20-T (Nacalai USA, USA) in a Tris-sorbitol buffer applying a modified method of Suzuki and Iwahashi ${ }^{22}$.

\section{Results and discussion}

In order to ascertain the effects of the MM minimal medium as a fermentation medium for $L i$ pomyces starkeyi, two cultivation strategies were investigated. Firstly, two repeated fed-batch cultivation experiments were conducted with 3 feeding pulses of glucose. For feed batch fermentations, the MM with the $90 \mathrm{~g} \mathrm{~L}^{-1}$ initial glucose concentration and the initial $339 \mathrm{C} / \mathrm{N}$ ratio was used. Secondly, a series of continuous cultivations was carried out using two different dilution rates $\left(0.06 \mathrm{~h}^{-1}\right.$ and 0.02 $\mathrm{h}^{-1}$ ) and two different $\mathrm{C} / \mathrm{N}$ ratios (113 and 56).

\section{Repeated fed-batch cultivation}

The repeated fed-batch cultivation resulted in a maximum cell density of $22.7 \mathrm{~g} \mathrm{~L}^{-1}$ (306 hours) and a maximum lipid concentration of $11.67 \mathrm{~g} \mathrm{~L}^{-1}$ (330 hours), respectively. Maximum cell density of 20.5 $\mathrm{g} \mathrm{L}^{-1}$ (144 hours) was achieved utilizing the initial glucose in the medium; subsequent additions of glucose resulted in variable production of cell mass and lipids (Fig. 1). Each feeding reduces the concentration of cells and lipids due to the increase in volume, but both cells and lipids generally increase to their previous concentrations. An extended lag phase of $24 \mathrm{~h}$ exhibited by both cultures, which is a contrast with $16 \mathrm{~h}$ observed for batch culture by ${ }^{2}$, could be an indication that the yeast cells were experiencing a shock resulting from increased substrate concentrations. Such a culture shock can explain the production of a byproduct ${ }^{23}$. The production of a byproduct results in a discoloration of the culture and an increased viscosity of the medium. Similar behavior of discoloration and increased viscosity changes was also observed by Koller et al. ${ }^{24}$ with the bacterial strain Haloferax mediterranei during the synthesis poly(3-hydroxybutyrate-co-3-hydroxyvalerate) and extracellular polysaccharide. The byproduct concentration reaches a maximum of $39.5 \mathrm{~g} \mathrm{~L}^{-1}$. SEM imaging of the freeze-dried broth indicated that the produced substance is localized outside the cells, and treatment with the zymolyase 


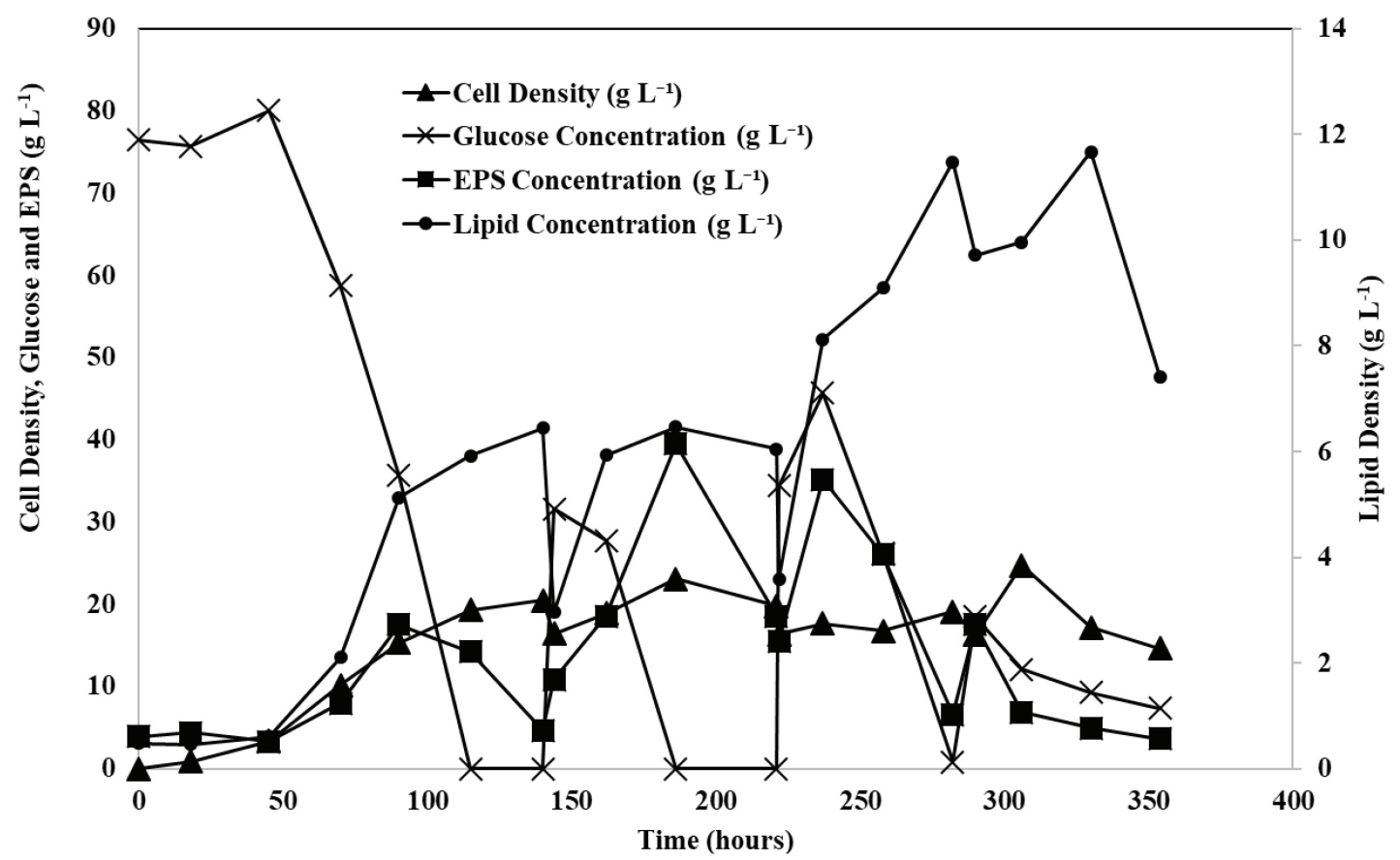

Fig. 1 - Cell density, lipid concentration, glucose concentration, and polysaccharide production by L. starkeyi during repeated fed-batch cultivation in the MM with glucose

enzyme cocktail results in its almost complete breakdown and removal (Fig. 2). Interestingly, there is almost a 10 -fold reduction in the fluorescence intensity observed in the presence of the byproduct even though the cell lipid content does not decrease. There is no literature evidence on an impact of other chemicals on the cell permeability to Nile Red, but the difference in fluorescence intensity for similar lipid content depending on the presence or absence of the byproduct lends credence to the idea.

The finding that zymolyase enzyme can breakdown the produced compound, in combination with the FTIR analysis (Fig. 3) indicates that the produced material is an exopolysaccharide (EPS). The FTIR peaks of interest include $3500-3200 \mathrm{~cm}^{-1}$ (-OH group), $3000-2850 \mathrm{~cm}^{-1}$ (C-H stretch), 1470 $-1450 \mathrm{~cm}^{-1}$ (C-H bend), $1370-1350 \mathrm{~cm}^{-1}(\mathrm{C}-\mathrm{H}$ rock), and $1320-1000 \mathrm{~cm}^{-1}$ (C-O stretch), all indicating a possible saccharide ${ }^{25}$. Comparison with FTIR spectra of common mono- and di-saccharides reveale that the polysaccharide possibly contains mannose and galactose due to peak similarity. Alternative methods of polysaccharide extraction were considered, including water boiling and acid bath ${ }^{26}$. Both methods were evaluated by SEM imaging, as indicated in Fig. 2. Based on the images, it can be concluded that the acid bath did not digest the polysaccharide, but did digest the cellular matter, resulting in the pockmarked texture. The water boiling method only partially removed polysaccharide surrounding the cells. This could be an indication that measurement of the polysaccharide, following fil- tration of cells, does not necessarily capture the total content of produced exopolysaccharides.

The solubility testing with common organic solvents revealed that the polysaccharide is soluble in water, but insoluble in methanol, ethanol, toluene, tetrahydrofuran, dimethyl sulfoxide, and dichloromethane. The effect of selected solvents (THF and toluene) in the cell broth is presented in Fig. 2, showing that the solvents do not significantly change the surface of the freeze-dried cells. MALDI-TOF MS analysis of the precipitated EPS (Fig. 4) indicates peaks primarily in the $680-880$ Dalton size. Considering 180 Dalton molecular mass per hexose, and 194 Dalton molecular mass for uronic acids, approximately 4-5 repeating units are expected to form the structure of the polymer. The peaks from $850 \mathrm{~cm}^{-1}$ to $1100 \mathrm{~cm}^{-1}$ in the FTIR spectra also indicate that that some of the moieties are uronic acids ${ }^{27}$.

The polysaccharide and lipid production generally seems to share an inverse relationship. Although both increase following an addition of glucose, eventually, the EPS quantities seem to be declining, and the lipid quantities increasing. One possible explanation is that the yeast is actively consuming the EPS. L. starkeyi has the capability to produce polysaccharide hydrolyzing enzymes such as dextranase and amylase ${ }^{28}$. These enzymes could potentially be cleaving the polysaccharide back into its constituent monosaccharides (including mannose and galactose), which are then utilized by the yeast in lipid production. However, there is a fluctuation in EPS concentrations. One possible explanation is 

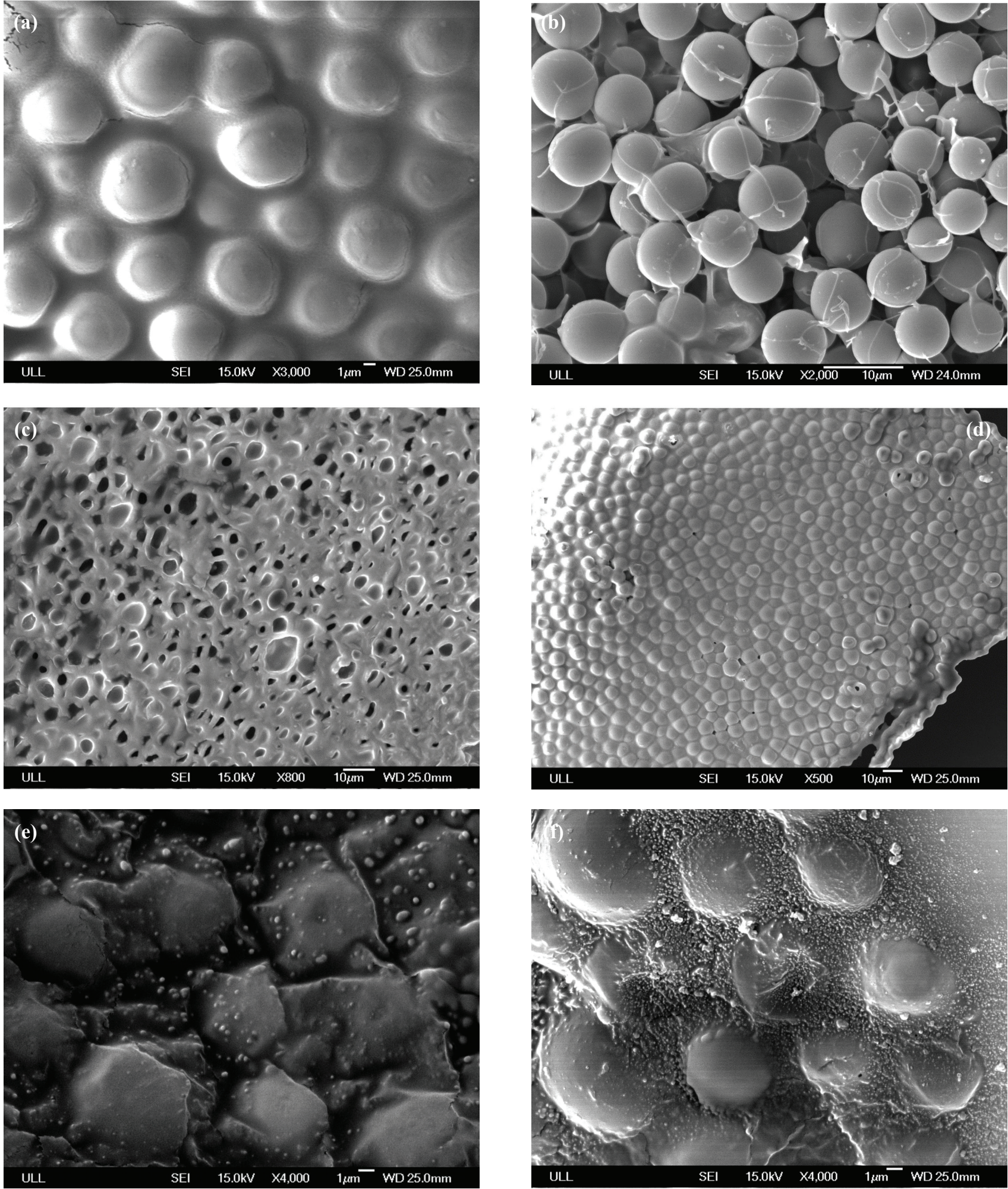

Fig. 2 - (a) SEM image of freeze-dried cells collected after repeated fed-batch experiment. Cells are seen encased in the EPS connective matter. (b) SEM image of freeze-dried, zymolyase-treated cells collected after repeated fed-batch experiment. Cells are stripped of the EPS connective matter. (c) SEM image of freeze-dried, acid-bath-treated cells collected after repeated fed-batch experiment showing EPS remaining after cell digestion. (d) SEM image freeze-dried, boiling-water-treated cells collected after repeated fed-batch experiment showing EPS remaining intact. (e) SEM image of freeze-dried cells mixed with THF. (f) SEM image of freeze-dried cells mixed with toluene. 


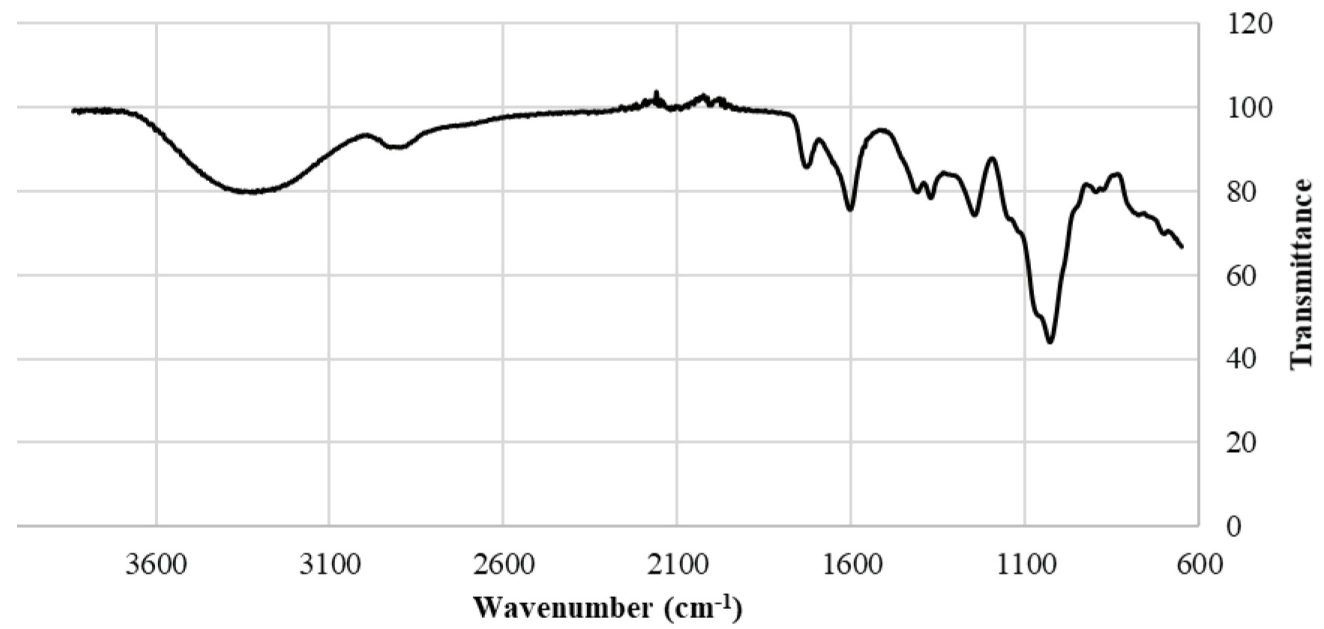

Fig. 3 - FTIR spectra of precipitated EPS from repeated fed-batch cultivation

the dilution of EPS during the addition of new batch of sugar. A second possible explanation could be consumption of EPS when glucose in the medium is limited, and the third possible explanation could be that the yeast species might be capable of producing both water soluble and water-insoluble polysaccharides, as has been reported for other species ${ }^{29}$. While transitions between the two polysaccharides can explain the changes in concentrations, the driving force behind this possible mechanism is unclear.

\section{Continuous cultivation}

The fermentation profiles obtained from the continuous cultivation of $L$. starkeyi in the MM are shown in Fig. 5. At the lower dilution rate and $\mathrm{C} / \mathrm{N}$ ratio, $83 \%$ of the glucose was consumed resulting in cell growth to $5 \mathrm{~g} \mathrm{~L}^{-1}$ with the lipid content of $40 \%$. At a higher dilution rate and $\mathrm{C} / \mathrm{N}$ ratio, only $43 \%$ of the glucose was consumed, reaching a cell mass of $5 \mathrm{~g} \mathrm{~L}^{-1}$ and lipid content of $46 \%$. Although Huang et al. ${ }^{30}$ have indicated that the dilution rate lower than $0.06 \mathrm{~h}^{-1}$ is normally required for optimal substrate-to-product conversions, our results show higher lipid concentrations at the $0.06 \mathrm{~h}^{-1}$ dilution rate. In contrast to the results of Anschau et al. ${ }^{7}$, the change in dilution rates does not seem to affect the stability of the cell concentration, but does affect the stability of the glucose concentration. Papaniko-

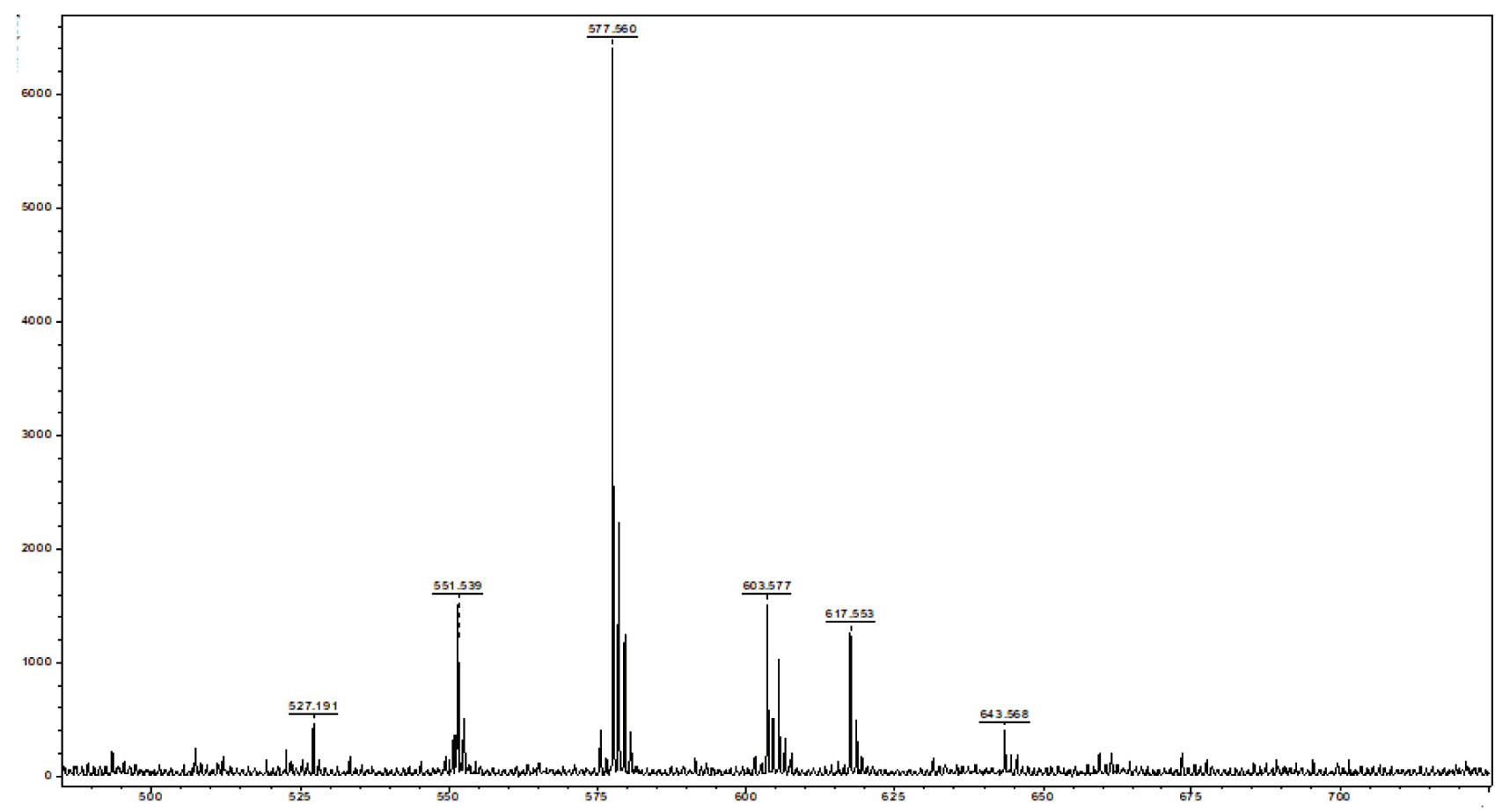

Fig. 4 - MALDI-TOF MS spectra of EPS separated from cell-broth by ethanol precipitation 

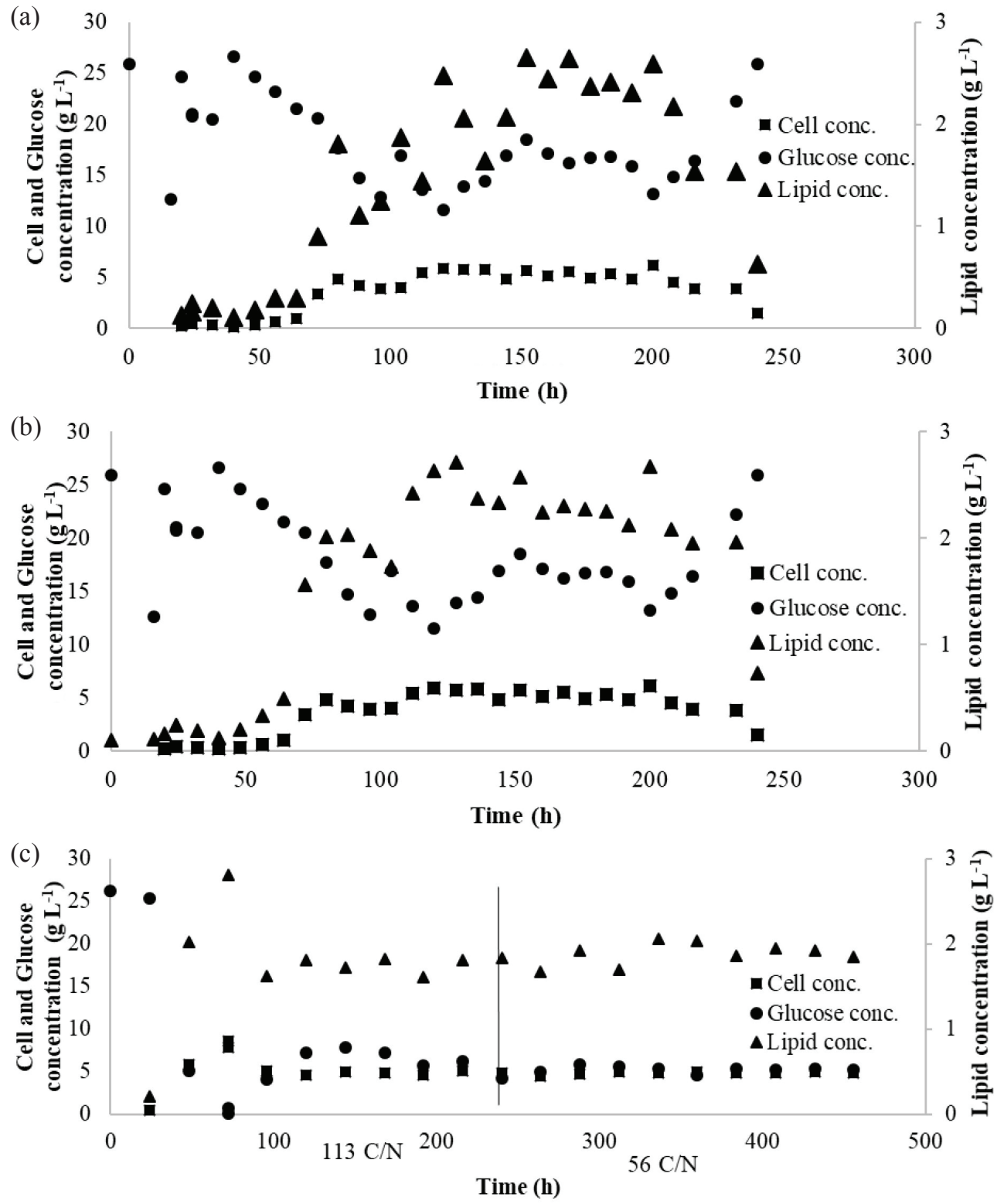

Fig. 5 - (a) Continuous cultivation of L. starkeyi at $0.06 h^{-1}$ dilution rate with C/N ratio of 113; (b) Continuous cultivation of $L$. starkeyi at $0.06 h^{-1}$ dilution rate with $C / N$ ratio of 56; (c) Continuous cultivation of L. starkeyi at $0.02 \mathrm{~h}^{-1}$ dilution rate with $C / N$ ratio of 113 and 56, respectively

laou and Aggelis ${ }^{31}$ indicated that a higher concentration of sugars that can be detected at high dilution rates results in an increased cell mass yield, but reduced lipid fraction.

The parameters characterizing the continuous cultivation are presented in Table 1 . The lag phase varied for the cultures from $24 \mathrm{~h}$ to $80 \mathrm{~h}$. Since this was longer than that for the batch culture, it could be an indication that the cells were undergoing some additional stress during the inoculation. The cell concentration, lipid concentration, cell productivity, and lipid productivity at the $0.06 \mathrm{~h}^{-1}$ dilution rate and $56 \mathrm{C} / \mathrm{N}$ ratio are comparable to that of Anschau et al. ${ }^{7}$, after adjusting for the difference in starting sugar concentration by a factor of $1: 2$. The effect of the change in $\mathrm{C} / \mathrm{N}$ ratios is seemingly negligible. Both the 113 and $56 \mathrm{C} / \mathrm{N}$ ratio media compositions show no markedly different changes in fermentation parameters. This finding is contrary to previous research, where the $\mathrm{C} / \mathrm{N}$ ratio had a noticeable impact on cell growth ${ }^{10,32}$. One potential explanation could be that the nitrogen supplied in the media is not consumed completely at the tested dilution rates, resulting in similar cell concentrations for the two $\mathrm{C} / \mathrm{N}$ ratios. Since the rate of cell growth is driven primarily by the availability of nitrogen for the production of important macromolecular components $^{33}$, the continued availability of nitrogen might result in similar cell growth profiles. Another possibility could be that, although the nitrogen in 
Table 1 - Cell productivity, lipid productivity, and glucose consumption for continuous cultivation of L. starkeyi

\begin{tabular}{lccccc}
\hline \multicolumn{1}{c|}{ C/N ratio } & 113 & 113 & 56 & 56 \\
\hline Dilution rate $\left(\mathrm{h}^{-1}\right)$ & 0.06 & 0.02 & 0.06 & 0.02 \\
Stable cell concentration $\left(\mathrm{g} \mathrm{L}^{-1}\right)$ & 5 & 5 & 5 & 5 \\
Stable lipid concentration $\left(\mathrm{g} \mathrm{L}^{-1}\right)$ & 2.3 & 1.9 & 2.3 & 2 \\
$\begin{array}{l}\text { Stable glucose concentration } \\
\left(\mathrm{g} \mathrm{L}^{-1}\right)\end{array}$ & 17 & 7 & 15 & 5 \\
Cell productivity $\left(\mathrm{g} \mathrm{L}^{-1} \mathrm{~h}^{-1}\right)$ & 0.313 & 0.0971 & 0.307 & 0.0987 \\
Lipid productivity $\left(\mathrm{g} \mathrm{L}^{-1} \mathrm{~h}^{-1}\right)$ & 0.138 & 0.0468 & 0.124 & 0.0410 \\
$\begin{array}{l}\text { Glucose consumption rate } \\
\left(\mathrm{g} \mathrm{L}^{-1} \mathrm{~h}^{-1}\right)\end{array}$ & 0.78 & 0.46 & 0.90 & 0.50 \\
Cell yield $\left(\mathrm{g} \mathrm{g}^{-1}\right)$ & 0.401 & 0.211 & 0.341 & 0.197 \\
Lipid yield $\left(\mathrm{g} \mathrm{g}^{-1}\right)$ & 0.177 & 0.102 & 0.138 & 0.082 \\
\hline
\end{tabular}

the media is consumed completely, the activity of AMP deaminase is sufficient at the culture conditions to maintain nitrogen availability ${ }^{34}$.

\section{Conclusions}

The study investigated the cell mass and lipid production of $L$. starkeyi using minimal medium under repeated fed-batch and continuous cultivation strategies. A maximal cell mass of $\sim 26 \mathrm{~g} \mathrm{~L}^{-1}$ and lipid concentration of $\sim 13 \mathrm{~g} \mathrm{~L}^{-1}$ were achieved using repeated fed-batch cultivation, along with exopolysaccharide production (max of $\sim 50 \mathrm{~g} \mathrm{~L}^{-1}$ ). The produced exopolysaccharide was found to likely be composed of 4-5 repeating units, with mannose and galactose. Continuous cultivations at $0.06 \mathrm{~h}^{-1}$ presented the highest yields and productivities and were comparable to $L$. starkeyi grown on media containing yeast extract. The results indicate that the developed minimal media is a comparable lowcost alternative to the Suutari media ${ }^{15}$ in continuous cultivation as well as repeated batch cultivation. However, the repeated fed-batch cultivation process, using the MM minimal medium, will need to be further investigated and adjusted, in order to overcome byproduct exopolysaccharide formation, or the economics of exopolysaccharide production process needs to be investigated since it has commercial value, before the minimal medium can be utilized in lipid production by $L$. starkeyi.

\section{ACKNOWLEDGMENTS}

This research work was mainly conducted in the Bioprocessing Research Laboratory of the Department of Chemical Engineering, University of Louisiana at Lafayette. The SEM images were cap- tured using the Microscopy Lab of the Department of Biology, University of Louisiana at Lafayette. The FTIR data was collected using the facilities of the Department of Chemistry, University of Louisiana at Lafayette. MALDI-TOF MS was performed by the Murray Mass Spectroscopy group in the Department of Chemistry, Louisiana State University. During this period, Mr. Venkatesh Thirumal was supported by Dr. Subramaniam's internal research fund as well as through the teaching assistantship from the University of Louisiana at Lafayette, Department of Chemical Engineering.

\section{References}

1. Ratledge, C., Regulation of lipid accumulation in oleaginous micro-organisms, Biochem. Soc. Trans. 30 (2002) 1047.

doi: https://doi.org/10.1042/bst0301047

2. Rahman, S., Arbter, P., Popovic, M., Bajpai, R., Subramaniam, $R$., Microbial lipid production from lignocellulosic hydrolyzates: Effect of carbohydrate mixtures and acid-hydrolysis byproducts on cell growth and lipid production by Lipomyces starkeyi, J. Chem. Technol. Biotechnol. 92 (2017) 1980. doi: https://doi.org/10.1002/jctb.5185

3. Oguri, E., Masaki, K., Naganuma, T., Iefuji, H., Phylogenetic and biochemical characterization of the oil-producing yeast Lipomyces starkeyi, Antonie van Leeuwenhoek 101 (2012) 359 . doi: https://doi.org/10.1007/s10482-011-9641-7

4. Naganuma, T., Uzuka, Y., Tanaka, K., Physiological factors affecting total cell number and lipid content of the yeast, Lipomyces starkeyi, J. Gen. Appl. Microbiol. 31 (1985) 29. doi: https://doi.org/10.2323/jgam.31.29

5. Gong, Z., Wang, Q., Shen, H., Hu, C., Jin, G., Zhao, Z. K., Co-fermentation of cellobiose and xylose by Lipomyces starkeyi for lipid production, Bioresour. Technol. 117 (2012) 20. doi: https://doi.org/10.1016/j.biortech.2012.04.063

6. Wild, R., Patil, S., Popović, M., Zappi, M., Dufreche, S., Bajpai, R., Lipids from Lipomyces starkeyi, Food Technol. Biotechnol. 48 (2010) 329.

7. Anschau, A., Xavier, M. C., Hernalsteens, S., Franco, T. T., Effect of feeding strategies on lipid production by Lipomyces starkeyi, Bioresour. Technol. 157 (2014) 214. doi: https://doi.org/10.1016/j.biortech.2014.01.104

8. Ratledge, C., Cohen, Z., Microbial and algal oils: Do they have a future for biodiesel or as commodity oils?, Lipid Technology 20 (2008) 155. doi: https://doi.org/10.1002/lite.200800044

9. Zhao, X., Hu, C., Wu, S., Shen, H., Zhao, Z. K., Lipid production by Rhodosporidium toruloides Y4 using different substrate feeding strategies, J. Ind. Microbiol. Biotechnol. 38 (2011) 627. doi: https://doi.org/10.1007/s10295-010-0808-4

10. Braunwald, T., Schwemmlein, L., Graeff-Honninger, S., French, W. T., Hernandez, R., Holmes, W. E., Claupein, W., Effect of different $\mathrm{C} / \mathrm{N}$ ratios on carotenoid and lipid production by Rhodotorula glutinis, Appl. Microbiol. Biotechnol. 97 (2013) 6581. doi: https://doi.org/10.1007/s00253-013-5005-8 
11. Granger, L. M., Perlot, P., Goma, G., Pareilleux, A., Kinetics of growth and fatty acid production of Rhodotorula glutinis, Appl. Microbiol. Biotechnol. 37 (1992) 13. doi: https://doi.org/10.1007/BF00174195

12. Slodki, M. E., Wickerham, L. J., Extracellular polysaccharides and classification of the genus Lipomyces, J. Gen. Microbiol. 42 (1966) 381

doi: https://doi.org/10.1099/00221287-42-3-381

13. Chang, H. N., Jung, K., Choi, J. D., Lee, J. C., Woo, H. C., Multi-stage continuous high cell density culture systems: A review, Biotechnol. Adv. 32 (2014) 514. doi: https://doi.org/10.1016/j.biotechadv.2014.01.004

14. Yamauchi, H., Mori, H., Kobayashi, T., Shimizu, S., Mass-production of lipids by Lipomyces starkeyi in microcomputer-aided fed-batch culture, Ferment. Technol. 61 (1983) 275

15. Suutari, M., Priha, P., Laakso, S., Temperature shifts in regulation of lipids accumulated by Lipomyces starkeyi, J. Am. Oil Chem. Soc. 70 (1993) 891. doi: https://doi.org/10.1007/BF02545349

16. Subramaniam, R., Liu, J., Dufreche, S., Zappi, M., Bajpai, $R$. (2012) Production and Economics of Microbial Oils. December 27-30, Chemcon 2012, 65th Annual Session of the Indian Institute of Chemical Engineers, India.

17. Rahman, S., Subramaniam, R., Dufreche, S., Zappi, M., Bajpai, R., Phosphate optimization for economical lipid production from Lipomyces starkeyi grown on starch, 287493, AIChE Annual Meeting, 2012.

18. Kimura, K., Yamaoka, M., Kamisaka, Y., Rapid estimation of lipids in oleaginous fungi and yeasts using Nile red fluorescence, J. Microbiol. Methods 56 (2004) 331 doi: https://doi.org/10.1016/j.mimet.2003.10.018

19. Folch, J., Lees, M., Sloane-Stanley, G., A simple method for the isolation and purification of total lipids from animal tissues, J. Biol. Chem. 226 (1957) 497.

20. Daines, T. L., Morse, K. W., A spectrophotometric method for determination of glucose in blood serum. A freshman laboratory experiment for medically and biologically oriented students, J. Chem. Educ. 53 (1976) 126 doi: https://doi.org/10.1021/ed053p126

21. Nielsen, $S$. S. in Phenol-Sulfuric Acid Method for Total Carbohydrates, Springer, 2010, pp. 47. doi: https://doi.org/10.1007/978-1-4419-1463-7_6

22. Suzuki, T., Iwahashi, Y., RNA preparation of Saccharomyces cerevisiae using the digestion method may give misleading results, Appl. Biochem. Biotechnol. 169 (2013) 1620.

doi: https://doi.org/10.1007/s12010-012-0051-8

23. Zhang, Y., Ma, H., Niu, Q., Chen, R., Hojo, T., Li, Y.-Y., Effects of substrate shock on extracellular polymeric sub- stance (EPS) excretion and characteristics of attached biofilm anammox granules, RSC Advances 6 (2016) 113289. doi: https://doi.org/10.1039/C6RA20097D

24. Koller, M., Chiellini, E., Braunegg, G., Study on the production and re-use of poly(3-hydroxybutyrate-co-3-hydroxyvalerate) and extracellular polysaccharide by the $A r$ chaeon Haloferax mediterranei strain DSM 1411, Chem. Biochem. Eng. Q. 29 (2015) 87. doi: https://doi.org/10.15255/CABEQ.2014.2058

25. Kačuráková, M., Mathlouthi, M., FTIR and laser-Raman spectra of oligosaccharides in water: Characterization of the glycosidic bond, Carbohydr. Res. 284 (1996) 145 doi: https://doi.org/10.1016/0008-6215(95)00412-2

26. Galanos, C., Lüderitz, O., Himmelspach, K., The partial acid hydrolysis of polysaccharides: A new method for obtaining oligosaccharides in high yield, The FEBS Journal 8 (1969) 332.

27. Coimbra, M. A., Barros, A., Barros, M., Rutledge, D. N., Delgadillo, I., Multivariate analysis of uronic acid and neutral sugars in whole pectic samples by FT-IR spectroscopy, Carbohydr. Polym. 37 (1998) 241

doi: https://doi.org/10.1016/S0144-8617(98)00066-6

28. Lee, J. H., Kim, G., Kim, S. H., Cho, D. L., Kim, D. W., Day, D. F., Kim, D., Treatment with glucanhydrolase from Lipomyces starkeyi for removal of soluble polysaccharides in sugar processing, J. Microbiol. Biotechnol. 16 (2006) 983.

29. Decker, E. M., Dietrich, I., Klein, C., von Ohle, C., Dynamic production of soluble extracellular polysaccharides by Streptococcus mutans, Int. J. Dent. 2011 (2011) 435830. doi: https://doi.org/10.1155/2011/435830

30. Huang, C., Zong, M. H., Wu, H., Liu, Q. P., Microbial oil production from rice straw hydrolysate by Trichosporon fermentans, Bioresour. Technol. 100 (2009) 4535. doi: https://doi.org/10.1016/j.biortech.2009.04.022

31. Papanikolaou, S., Aggelis, G., Lipid production by Yarrowia lipolytica growing on industrial glycerol in a single-stage continuous culture, Bioresour. Technol. 82 (2002) 43. doi: https://doi.org/10.1016/S0960-8524(01)00149-3

32. Esser, M., in Effect of $\mathrm{C} / \mathrm{N}$ Ratio on Enzymatic Activity for Microbial Lipid Production, Vol. University for Applied Sciences, Berlin, 2015

33. Evans, C. T., Ratledge, $C$., Influence of nitrogen metabolism on lipid-accumulation by Rhodosporidium toruloides CBS14, J. Gen. Microbiol. 130 (1984) 1705

34. Evans, C. T., Ratledge, C., Possible regulatory roles of ATP:citrate lyase, malic enzyme, and AMP deaminase in lipid accumulation by Rhodosporidium toruloides CBS 14, Can. J. Microbiol. 31 (1985) 1000. doi: https://doi.org/10.1139/m85-189 